\title{
EU:n yhteinen maatalouspolitiikka ja Suomen maatalous vuoteen 2020
}

\author{
Jyrki Niemi $^{1}$ ja Lauri Kettunen ${ }^{1}$ \\ ${ }^{1}$ MTT Taloustutkimus, Luutnantintie 13,00410 Helsinki, jyrki.niemi@mtt.fi
}

\section{Tiivistelmä}

Suomen maa- ja elintarviketalouden toimintaedellytyksiin merkittävästi vaikuttavasta yhteisestä maatalouspolitiikasta (YMP), sen suunnasta ja sisällöstä vuoteen 2020 saakka päästiin poliittiseen yhteisymmärrykseen kesäkuussa 2013. Euroopan komissio, Eurooppa-neuvosto ja Euroopan parlamentti saivat viimein sovitettua yhteen kantansa kaksi vuotta kestäneiden ja loppua kohti yhä intensiivisemmiksi käyneiden neuvottelujen jälkeen. Neuvottelujen tuloksena syntynyt sopimus luo perustan vuonna 2015 alkavalle uudelle EU:n yhteiselle maatalouspolitiikalle, joka merkitsee suorien tukien "viherryttämistä” sekä tukien jakamista aiempaa tasaisemmin eri jäsenvaltioiden kesken.

Tässä tutkimuksessa tarkastellaan minkälaisia muutoksia, haasteita ja mahdollisuuksia yhteisen maatalouspolitiikan uudistus aiheuttaa Suomen maa- ja elintarviketaloudelle. Keskeistä tutkimuksellisesti on arvioida maataloustuotannon ja -tulojen ja tilamäärän kehitysnäkymiä Suomessa vuoteen 2020 saakka. Analyysit maataloustuotannon ja -tulon tulevasta kehityksestä tehdään AGMEMODmallilla, joka on kehitetty osana laajempaa EU-rahoitteista hanketta jossa MTT taloustutkimus on mukana (http://www.tnet.teagasc.ie/agmemod/). AGMEMOD-malli on 28 jäsenmaata käsittävä EU:n maataloutta kuvaava ekonometrinen markkinamalli. Mallin avulla analysoidaan markkina- ja politiikkamuutosten vaikutuksia EU:n maatalous- ja elintarvikemarkkinoihin. Malli on rekursiivisdynaaminen, ja siinä otetaan huomioon politiikkamuutosten ohella mm. tuottavuuden ja tuotannon tehokkuuden kasvu sekä muutokset kulutustottumuksissa. Tuottavuus kasvaa mallissa satotason ja eläinten keskituotosten noustessa.

Vaikutusanalyysit osoittavat maataloustuotteiden tuotannon pysyvän Suomessa keskimäärin nykyisellä tasolla vuoteen 2020, mikäli maataloustuotteiden hintakehitys vastaa tuotantopanosten hintakehitystä ja maatalouden tukijärjestelmä säilyy ennallaan. Kotimainen maidontuotanto jää AGMEMOD-mallin ennusteessa jonkin verran nykyistä alemmaksi. Jo aiemmin tehdyt politiikkauudistukset heikentävät maidon tarjontaa Suomessa. Maitokiintiöistä luopuminen vuonna 2015 on siten kohtuullisen hyvistä kysyntä- ja markkinanäkymistä huolimatta haasteellinen Suomen maitosektorille, mikä korostaa maidon hintatason ja kansallisen tuen merkitystä Suomen maitosektorille. Naudanlihantuotannon, joka on Suomessa erittäin riippuvainen lypsylehmien lukumäärästä, ennustetaan säilyvän nykyisellä noin 80 milj. kg tasolla vuosina 2013-2020. Sianlihantuotannon ennustetaan alenevan ja laskevan alle kotimaisen kulutuksen tason. Siipikarjanlihantuotanto sitä vastoin nousee edelleen kasvavan kulutuksen tahdissa. Maatalouden rakennekehitykseen ja sitä kautta tuottavuuskehityksen nopeuteen maatalouspolitiikan muutoksilla arvioidaan olevan hyvin vähän vaikutusta. Maatalouden rakennekehitys jatkuu tulevina vuosina nopeana yksikkökokojen kasvaessa ja tilalukumäärän pienentyessä.

\section{Asiasanat}

EU, maatalouspolitiikka, Suomi, tuotanto, rakenne, maataloustulo. 


\section{Johdanto}

Suomen maa- ja elintarviketalouden toimintaedellytyksiin merkittävästi vaikuttavasta yhteisestä maatalouspolitiikasta (YMP), sen suunnasta ja sisällöstä vuoteen 2020 saakka päästiin poliittiseen yhteisymmärrykseen 26. kesäkuuta 2013. Euroopan komissio, Eurooppa-neuvosto ja Euroopan parlamentti saivat viimein sovitettua yhteen kantansa kaksi vuotta kestäneiden ja loppua kohti yhä intensiivisemmiksi käyneiden neuvottelujen jälkeen. Euroopan parlamentti hyväksyi sopimuksen muodollisesti 24. syyskuuta 2013.

Neuvottelujen tuloksena syntynyt sopimus luo perustan vuonna 2015 alkavalle uudelle EU:n yhteiselle maatalouspolitiikalle, joka merkitsee suorien tukien "viherryttämistä" sekä tukien jakamista aiempaa tasaisemmin eri jäsenvaltioiden kesken. Perustavanlaatuista uudistusta odottaneista tahoista saavutettu sopimus tuntuu varmasti sangen maltilliselta, koska se säilyttää kaikki nykyisen yhteisen maatalouspolitiikan keskeiset elementit ja jopa vahvistaa niitä. Se ei ainoastaan pysäytä 2000-luvun ensimmäisen vuosikymmenen puolivälissä voimistunutta liberalisaatiokehitystä, vaan joissain suhteissa suorastaan kääntää "kelloa taaksepäin". Uudistus nimittäin mahdollistaa jopa jonkinasteisen YMPtukien uudelleenkytkemisen tiettyjen hyödykkeiden tuottamiseen.

Käsillä olevassa artikkelissa tarkastellaan minkälaisia muutoksia, haasteita ja mahdollisuuksia yhteisen maatalouspolitiikan uudistus aiheuttaa Suomen maa- ja elintarviketaloudelle. Tutkimuksessa arvioidaan miten uudistuksen mukanaan tuomat keskeisimmät muutokset vaikuttavat suomalaiseen maataloustuotantoon. Keskeistä tutkimuksellisesti on arvioida maataloustuotannon ja -tulojen ja tilamäärän kehitysnäkymiä Suomessa vuoteen 2020 saakka.

Analyysit maataloustuotannon ja -tulon tulevasta kehityksestä tehdään AGMEMOD-mallilla, joka on kehitetty osana laajempaa EU-rahoitteista hanketta, jossa MTT taloustutkimus on mukana (http://www.agmemod.eu). AGMEMOD-malli on tarkoitettu politiikkamuutosten vaikutusten tarkasteluun. Mallin tuottamia tuloksia ei tule pitää tarkkoina ennusteina tulevasta kehityksestä vuoteen 2020, vaan tämänhetkisinä kehitystrendeinä ja niitä tulee tarkastella suhteessa tehtyihin oletuksiin. Vaikutusanalyyseissa joudutaan tekemään oletuksia niin tuotteiden ja tuotantopanosten hintakehityksestä kuin kansallisesta maatalouspolitiikastakin vuoden 2013 jälkeen.

\section{Aineisto ja menetelmä}

AGMEMOD-malli on 28 jäsenmaata käsittävä EU:n maataloutta kuvaava ekonometrinen markkinamalli. Mallin avulla analysoidaan markkina- ja politiikkamuutosten vaikutuksia EU:n maatalous- ja elintarvikemarkkinoihin (Chantreuil ym. 2012). Malli on rekursiivis-dynaaminen ja siinä otetaan huomioon politiikkamuutosten ohella mm. tuottavuuden kasvu sekä muutokset kulutustottumuksissa. Tuottavuus kasvaa mallissa satotason ja eläinten keskituotosten noustessa (Chantreuil ym. 2005, 2008, Bartova ja M'barek 2007).

AGMEMOD-mallin tärkeimpiä tarkastelukohteita ovat maataloustuotteiden tuotanto, kulutus, ulkomaankauppa ja varastojen taso. Tärkeimpiä kehitykseen vaikuttavia tekijöitä ovat tuote- ja panoshintojen muutokset, jotka vaikuttavat eläinten ruokintaan, tuotostasoon ja pellonkäyttöön, ts. hintasuhteiden muutoksiin sopeudutaan maatalouden sisällä. Mallin tuottamat trendit riippuvat myös makromuuttujien (BKT:n kasvu, hintojen yleinen kehitys, väestön kasvu, valuuttakurssit) kehityksestä.

AGMEMOD-mallin perustan muodostavat kansalliset maatalousmallit, jotka on yhdistetty koko EU-alueen kattavaksi malliksi (Kuvio 1). Kansalliset mallit on liitetty toisiinsa EU:ssa vallitsevina olevien hintojen, ns. avainhintojen avulla. Kullekin tuotteelle on määritelty maa, jonka hinta on määräävässä asemassa EU:ssa, eli jonka hinnasta jäsenmaiden hinta on riippuvainen. Kytkentämalli ratkaisee EU:n markkinahinnat (mallin avainhinnat), jotka tasapainottavat hyödykemarkkinat koko EU:n tasolla (Salamon ym. 2008). Avainhintojen (pääosin Ranskan ja Saksan hintojen) tasoon vaikuttavat EU:n sisäisen kysyntä- ja tarjontatilanteen lisäksi maailmanmarkkinahintojen ja valuuttakurssien kehitys ja EU:n ulkomaankauppaa koskevat säännökset kuten tullit ja tuontimaksut. Malli olettaa maailmanmarkkinahinnat annetuiksi, joten ne ovat tärkeitä skenaariomuuttujia.

MTT taloustutkimuksessa on rakennettu muiden maamallien kanssa riittävässä määrin yhteensopiva ekonometrinen malli Suomen maataloudesta (Niemi ym. 2005). Se on Suomen maatalouden päätuotantosuunnat ja niiden ulkomaankaupan kattava malli, jossa on tarkka EU-tukipolitiikan kuvaus. 
Parametrien arvot on saatu malliin estimoimalla annetuista aikasarjoista. Malli on validoitu, ts. sovitettu tuotannon ja hintojen toteutuneeseen kehitysuraan 1995-2012, käyttäen perusteina ensisijassa havaittuja tuotantomäärien ja tuottajahintojen kehitystä. Validoinnissa on hyödynnetty myös ns. asiantuntijamenettelyä, jossa yleisesti hyväksyttyjä kysyntä- ja tarjontajoustoja käytetään mallin parametrien (regressiokertoimien) määrittämiseen.

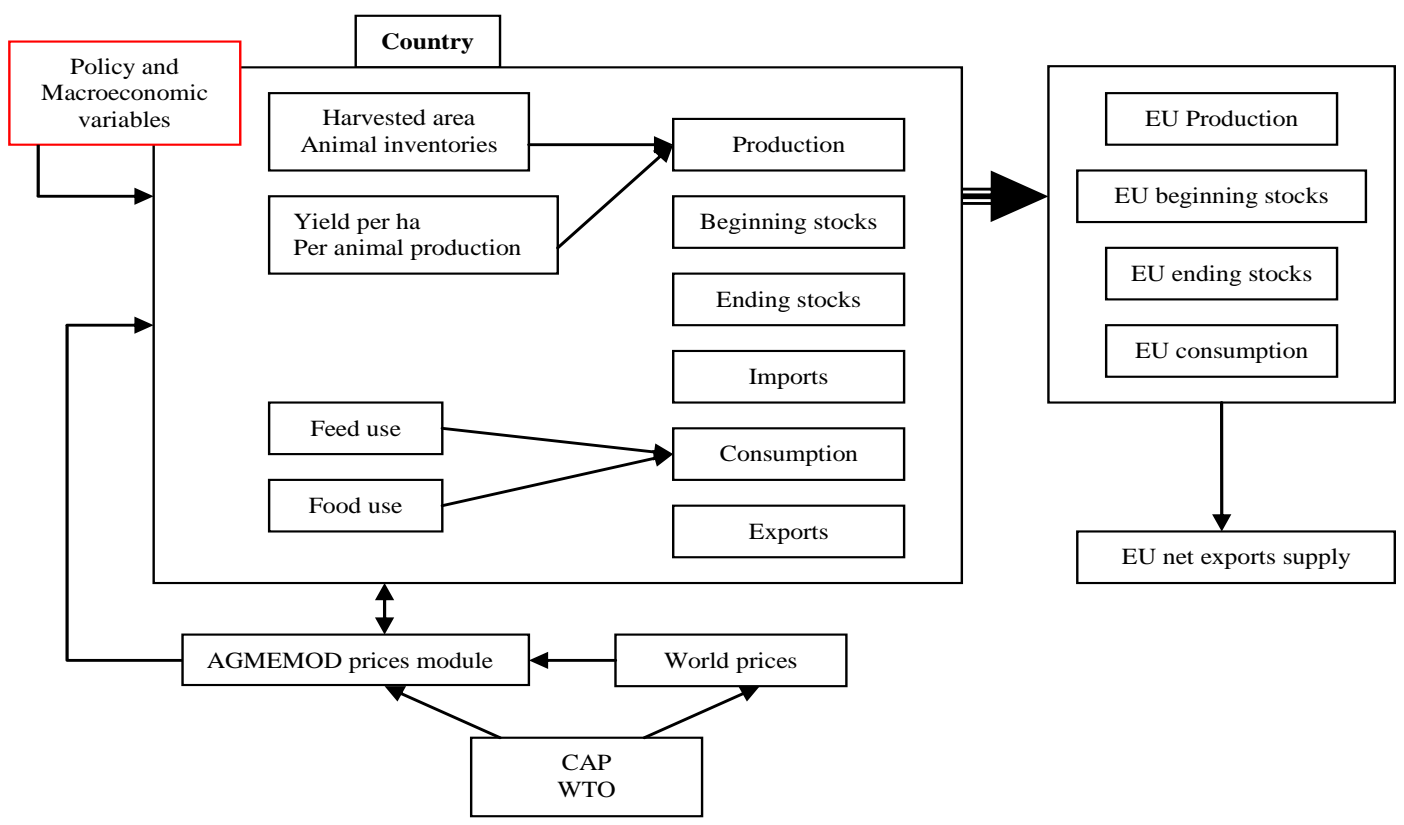

Kuvio 1. AGMEMOD-mallin perusrakenne.

\section{Tulokset ja tulosten tarkastelu}

Suomen kokonaisvilja-ala säilyy AGMEMOD-mallin ennusteen mukaan melko vakaana keskipitkällä aikavälillä. Vilja-ala on ollut lähellä 1,1 milj. hehtaaria ja se alenee hieman vuoteen 2020 mennessä (Kuvio 2). Ohran ja kauran alat alenevat lähes samassa suhteessa kokonaisalan kanssa. Vehnän alan ennustetaan puolestaan nousevan hieman. Ruisala säilyy ennallaan. Vuosittaiset vaihtelut voivat toki poiketa huomattavasti hintatekijöistä johtuen. Eri viljojen alat vaihtelevat myös vuosittain mm. kylvöja korjuuoloista riippuen.

Viljelyalan pienentymisestä huolimatta viljan kokonaistuotanto ei juuri vähene, sillä satotaso vastaavasti nousee. Viljojen satotaso määräytyy mallissa pääasiassa trendin mukaan, mutta myös hinta on mukana satotasoyhtälössä. Oletetun keskisadon kasvun seurauksena kaikkien viljojen satotaso hehtaaria kohden kasvaa vuoteen 2020 mennessä.

Maidontuotanto jää AGMEMOD-mallin tulosten mukaan vuonna 2020 noin $5 \%$ alemmalle tasolle kuin vuonna 2012 (Kuvio 2). Tiedossa olevat maatalouspolitiikan muutokset perusskenaariossa, erityisesti maitokiintiöistä luopuminen vuoteen 2015 , ovat maitotuotteiden kohtuullisen hyvistä kysyntä- ja markkinanäkymistä huolimatta haasteellisia Suomen maitosektorille. Jo aiemmin tehdyt politiikkauudistukset (vuonna 2006 toteutettu CAP -reformi) heikentävät maidon tarjontaa Suomessa (Lehtonen 2007). Kannustinongelmaa kärjistää tapahtunut viljan hinnan nousu. Tämä korostaa maidon hintatason ja kansallisen tuen merkitystä Suomen maitosektorille.

Vuonna 2012 maitoa tuotettiin 2 230milj. litraa maitoa. Määrä oli lähes $6 \%$ pienempi kuin vuonna 2005. Keskituotos on noussut pitkän ajan lähes suoraviivaisesti, mutta vuosina 2007-2009 on tässä kehityksessä ollut poikkeamia, eikä pitkänajan trendisuoraa enää voidakaan jatkaa entiseen tapaan, vaan kasvuennustetta on taitettu niin, että keskituotos on nyt vain 8500 1/lehmä vuonna 2020. 


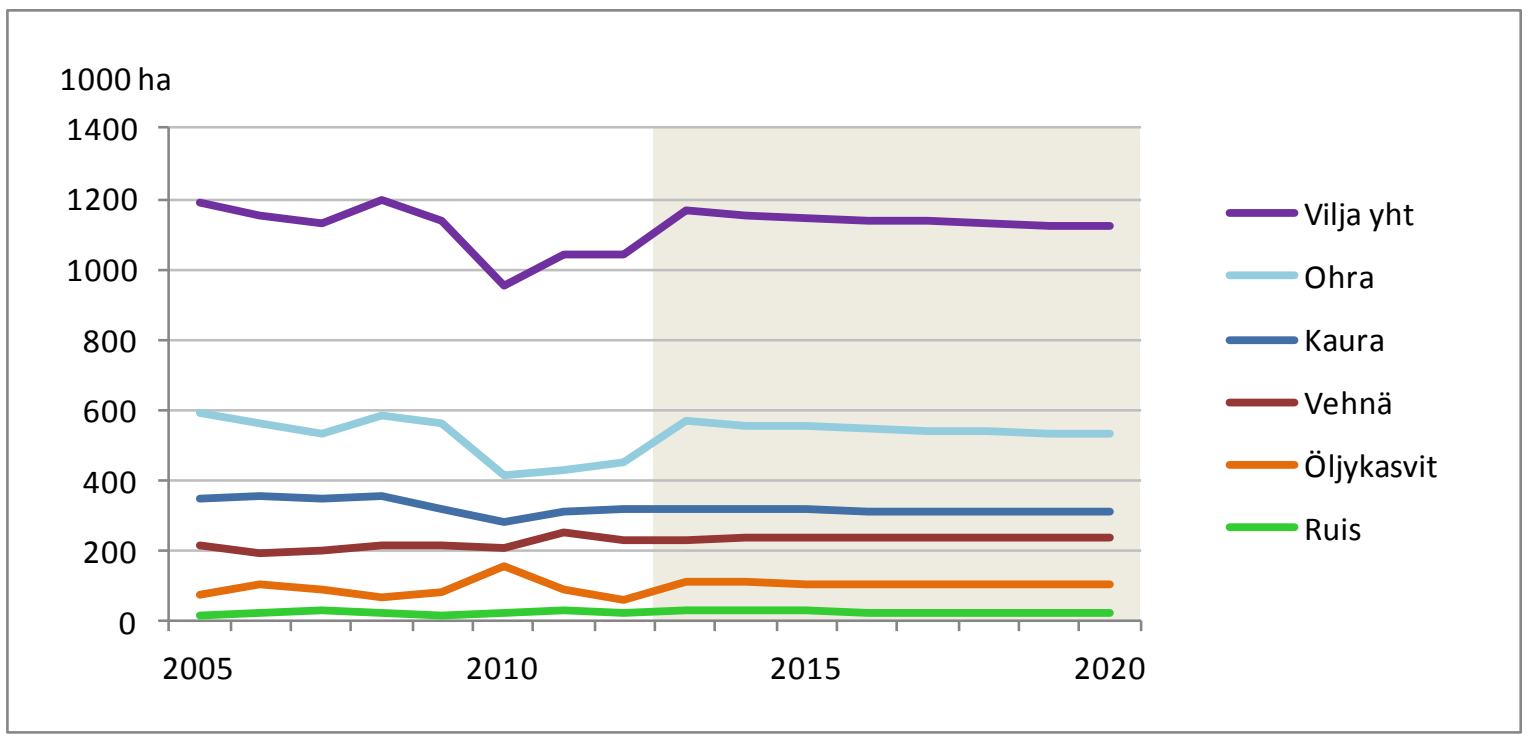

Kuvio 2. Viljantuotannon kokonaisala AGMEMOD-mallissa vuosina 2005-2020 (1000 ha).

Lypsylehmien lukumäärä, mistä naudanlihantuotanto riippuu mitä suurimmassa määrin, on vähentynyt maidontuotannon vähenemisen ja lypsylehmien keskituotoksen kasvun seurauksena. Niinpä naudanlihantuotanto vähentyi 87 miljoonan kilon tasolta vuonna 2005 yhteensä lähes $7 \%$ vuoteen 2012 mennessä, jääden noin 81 miljoonaan kiloon. Tuotantomäärä säilyy AGMEMOD-mallin tulosten mukaan noin 80 milj. kg tasolla vuosina 2013-2020. Toisin sanoen emolehmätuotannon kasvun ennustetaan riittävän korvaamaan lypsylehmien lukumäärän vähenemisestä aiheutuvaa naudanlihantuotannon supistumista.

Emolehmätuotannon yleistyminen on EU-jäsenyysvuosien aikana selvästi hidastanut naudanlihantuotannon vähenemistä. Emolehmien määrä on yli kaksinkertaistunut tällä vuosituhannella. Naudanlihantuotantoon tarkoitettuja emolehmiä on nykyisin jo noin 60000 ja sieltä tulevien vasikoiden lukumäärä kaikkiaan noin 16 prosenttia koko maan vasikkamäärästä.

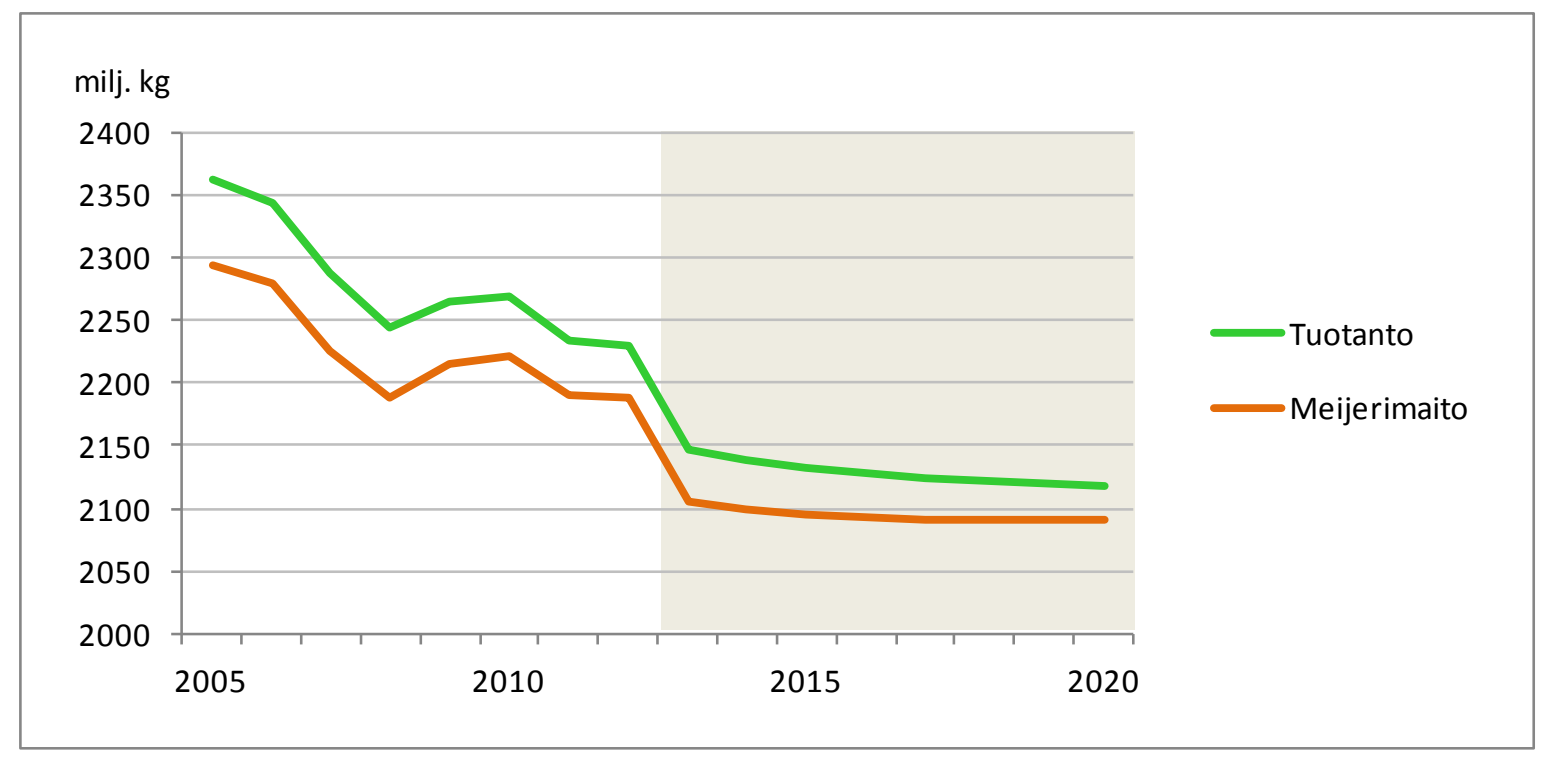

Kuvio 3. Maidon kokonaistuotannon kehitys AGMEMOD-mallissa vuosina 2005-2020 (milj. litraa). 
Vuonna 2012 Suomessa tuotettiin sianlihaa lähes 192 milj. kg ja kulutettiin 195 milj. kg. AGMEMOD-mallin tulosten mukaan sianlihaa ennustetaan tuotettavan Suomessa myös keskipitkällä aikavälillä noin 192-188 milj. kiloa. Sianlihan kulutus puolestaan nousee yli 200 milj. kg vuoteen 2020 mennessä, joten alituotantotilanteesta tulisi näin ollen pysyvä. Ennusteen toteutumiseen on kuitenkin suhtauduttava suurella varauksella. Sianlihantuotanto ovat varsin joustava, joten mallin tuottamat pitkän aikavälin ennusteet eivät ole tästä näkökulmasta kovin luotettavia.

Siipikarjanlihantuotanto on ollut viime vuosina voimakkaassa kasvussa. Tuotanto on kasvanut Suomessa vuodesta 2005 vuoteen 2012 yli 20 prosenttia. Vuonna 2012 siipikarjanlihaa tuotettiin 108 milj. kg ja kulutettiin 101 milj. kg. Siipikarjanlihantuotanto nousee AGMEMOD-mallin ennusteen mukaan edelleen kasvavan kulutuksen tahdissa. Vuoteen 2020 mennessä siipikarjanlihaa ennustetaan tuotettavan Suomessa lähes 120 milj. kg. Siipikarjanlihan kulutuksen ennustetaan kasvavan vastaaviin lukemiin.

Kananmunien tuotantomäärän ennustetaan AGMEMOD-mallissa puolestaan alenevan hieman ja pysyttelevän 55-56 milj. kg tasolla vuosina 2013-2020. Kananmunien kulutus henkeä kohti säilyy ennusteessa ennallaan ja kokonaiskulutus kasvaa väestön kasvua vastaavasti.

Maatalouden rakennekehityksen odotetaan puolestaan jatkuvan tulevina vuosina nopeana yksikkökokojen kasvaessa ja tilalukumäärän pienentyessä. Erityisesti kotieläintuotannossa rakennekehitys ja yksikkökoon kasvu jatkuu nopeana. Maatilojen määrä on vuodesta 1995 laskenut vuosittain keskimäärin kolmen prosentin vauhtia ja kotieläintaloudessa lähes seitsemän prosentin vuosivauhtia. Mikäli kotieläintilojen määrä alenee nykyistä nopeutta vuoteen 2020, kotieläintilojen määrä laskee alle 10000 tilaan, kun vuonna 2005 kotieläintiloja oli vielä yli 33 000. Maidontuotantoon erikoistuneiden tilojen määrä laskee noin 5500 tilaan vuoteen 2020 mennessä, kun vuonna 2005 niitä oli vielä yli 16000 (Kuvio 4).

Vuodesta 1992 vuoteen 2010 tarkasteltaessa maatalouden tuottavuus nousi keskimäärin yli prosentin vuodessa. Olettamalla rakennerationalisoinnin tuoman tuottavuuskasvun säilyvän yhden prosentin suuruisena myös aikajaksolla 2013-2020, maatalouden yrittäjätulo alenee, sillä tuotantokustannusten ennakoidaan nousevan lähes yleisen hintakehityksen mukaisesti markkinahintojen ja tukien säilyessä lähes ennallaan. Eksogeenisesti asetettu 1 prosentin tuottavuuden kasvu ei ole näin ollen riittävä inflaation ja kustannusten nousun kompensoimiseksi. Yrittäjätulo alenee mallissa 911 miljoonasta eurosta vuonna 2012 noin 750 miljoonaan euroon (-18 \%) vuoteen 2020 mennessä.

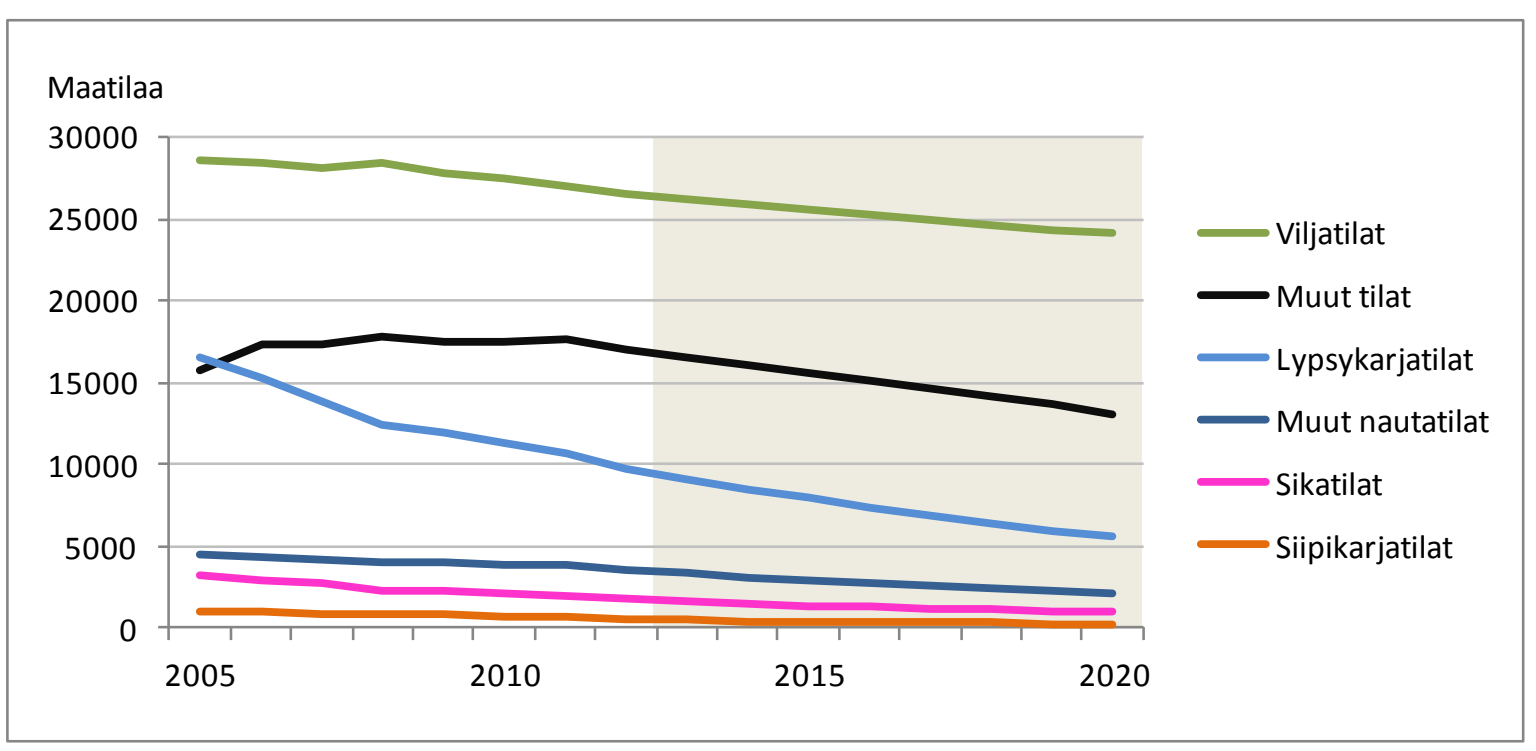

Kuvio 4. Maatilojen lukumäärän kehitysennuste eri tuotantosuunnissa vuosille 2005-2020. 


\section{Johtopäätökset}

Tässä tutkimuksessa on tarkasteltu minkälaisia muutoksia yhteisen maatalouspolitiikan uudistus aiheuttaa Suomen maa- ja elintarviketaloudelle. Tutkimuksellisesti keskeisintä on ollut analysoida maataloustuotannon ja -tulojen ja tilamäärän kehitysnäkymiä Suomessa vuoteen 2020 saakka. Tutkimuksessa on hyödynnetty analyysimenetelmänä EU:n maataloutta kuvaavaa ekonometrisen markkinamallia AGMEMODia. Analyysin tulokset osoittavat maataloustuotteiden tuotannon pysyvän Suomessa keskimäärin nykyisellä tasolla vuoteen 2020, mikäli maataloustuotteiden hintakehitys vastaa tuotantopanosten hintakehitystä ja maatalouden tukijärjestelmä säilyy ennallaan. Kotimainen maidontuotanto jää AGMEMOD-mallin ennusteessa jonkin verran nykyistä alemmaksi. Jo aiemmin tehdyt politiikkauudistukset heikentävät maidon tarjontaa Suomessa. Maitokiintiöistä luopuminen vuonna 2015 on siten kohtuullisen hyvistä kysyntä- ja markkinanäkymistä huolimatta haasteellinen Suomen maitosektorille, mikä korostaa maidon hintatason ja kansallisen tuen merkitystä Suomen maitosektorille. Naudanlihantuotannon, joka on Suomessa erittäin riippuvainen lypsylehmien lukumäärästä, ennustetaan säilyvän nykyisellä noin 80 milj. kg tasolla vuosina 2013-2020. Sianlihantuotannon ennustetaan alenevan ja laskevan alle kotimaisen kulutuksen tason. Siipikarjanlihantuotanto sitä vastoin nousee edelleen kasvavan kulutuksen tahdissa. Maatalouden rakennekehitykseen ja sitä kautta tuottavuuskehityksen nopeuteen maatalouspolitiikan muutoksilla arvioidaan olevan hyvin vähän vaikutusta. Maatalouden rakennekehitys jatkuu tulevina vuosina nopeana yksikkökokojen kasvaessa ja tilalukumäärän pienentyessä.

\section{Kirjallisuus}

Bartova, L. \& M'barek, R. 2007. Impact Analysis of CAP Reform on the Main Agricultural Commodities". Report I AGMEMOD - Summary Report. JRC Scientific and Technical Report. EUR Number: 22940 EN/1. 11/2007. Saatavissa internetistä: http://www.jrc.es/publications.

Chantreuil, F., Levert, F., Erjavec, E., Donnellan, T. \& Hanrahan, K. 2005. CAP Reform: Prospects for crop markets in the enlarged EU. EuroChoices, 4(1), pp 26-30.

Chantreuil, F., Donnellan, T., van Leeuwen, M., Salamon, P., Tabeau, A. \& Bartova, L. 2008. EU Dairy Quota Reform - AGMEMOD Scenario Analysis. 12th EAAE Congress, Ghent, August 2008.

Chantreuil, F., Hanrahan, K. \& van Leeuwen, M. 2012. The Future of EU Agricultural Markets by AGMEMOD. Springer. $122 \mathrm{~s}$.

Lehtonen, H. (toim.) 2007. EU:n maitokiintiöjärjestelmän poistumisen vaikutukset Suomen maitosektorille". MTT:n selvityksiä 144: 89 s. Saatavissa internetistä: http://www.mtt.fi/mtts/pdf/mtts144.pdf Verkkojulkaisu päivitetty 25.9.2007.

Niemi, J., Jansik, C., Kettunen, L. \& Lehtonen, H. 2005. A Tool to Analyse the Impact of Policy Changes on the Agri-Food Sector of Finland. Teoksessa: Arfini, F. (toim.). Modelling agricultural policies: state of the art and new challenges. Proceedings of the 89th European Seminar of the European Asssociation of Agricultural Economists. pp. 609-629.

Niemi, J. \& Ahlstedt, J. (toim.) 2013. Suomen maatalous ja maaseutuelinkeinot 2013. MTT Taloustutkimus, julkaisuja 114. 96 s. Saatavissa internetistä:

https://portal.mtt.fi/portal/page/portal/mtt/mtt/julkaisut/suomenmaatalousjamaaseutuelinkeinot/jul114_SM2013. pdf.

Salamon, P., Chantreuil, F., Donnellan, T., Erjavec, E., Esposti, R., Hanrahan, K., van Leeuwen, M., Bouma, F., Dol, W. \& Salputra, G. 2008. How to deal with the challenges of linking a large number of individual national models: the case of the AGMEMOD Partnership. Agrarwirtschaft, Jahrgang 57 (2008), Heft 8. 